\title{
Constructive Assessment of an Attainable Accuracy at Large-Size Thin-Walled Housing Rings Machining by Modelling of Cutting Force Effect
}

\author{
S.V. Starovoitov*, M.E. Sattarov and S.Kh. Khadiullin \\ Ufa state aviation technical university, 12 build 8, K. Marks street, Ufa, Russia - 450008
}

Received 26 November 2019; Accepted 5 February 2020

\begin{abstract}
Large-size thin-walled housing rings machining accuracy problem was described. Produceability rating based on part stiffness was offered. Geometrical mechanical compliance simulation model of large-size thin-walled aviation engine housing rings was developed. Comparing of calculated geometrical mechanical compliance for different real parts and their experimental machining deviation was performed. The results of this comparing confirmed that geometrical mechanical compliance can be use as machining accuracy criteria for large-size thin-walled aviation engine housing rings. Geometrical mechanical compliance criteria value was found during real parts machining. This value shows the boundary parts design conditions when is necessary to use nonconventional technological decisions (tool, cutting mode, equipment, etc) to provide required machining accuracy.
\end{abstract}

Keywords: accuracy, stiffness, mechanical compliance, turning, housing ring, produceability, modelling, simulation model, rigidity, cutting force, machining quality.

\section{Introduction}

The main challenges of technical progress in the field of mechanical engineering is the increase of productivity and cost reduction of machine tools manufacturing parts. The market demand requires the ability to work in conditions of a large variety of manufactured products and a high frequency of products type change that resulted in the increase of flexibility, mechanical accuracy and productivity of currently used metal cutting machines. The main problem for the production was the lack of reliable and proven methods for creating technological processes that allow to achieve the required quality of the machined surfaces and the accuracy of their sizes with minimal cost and in the shortest possible time.

This problem is especially acute during the machining of parts of aircraft engines, the increased requirements of which determine the high cost of both serial production and increased costs at the stage of technological preparation [1]. Characteristics of the majority of parts of aviation engines are small rigidity and space and difficult geometry that is explained by aspiration to decrease in their weight on condition of maintaining utilization properties. In addition to traditionally expensive and difficult parts of the gas path in production high cost in modern aviation engines is got also by the case parts having the form of large-size thin-walled rings.

The forming accuracy during blade cutting of metals is largely determined by the system of forces acting on the workpiece during the cutting process. This is expressed in the occurrence of elastic deformation of the machined surface during chip formation, which leads to the appearance of an error in its geometric dimensions. In the case of processing non-rigid parts, the elastic deformation due to the influence of the cutting force can reach a value commensurate with the

\footnotetext{
*E-mail address: Sv_starov@mail.ru

ISSN: 1791-2377 @ 2020 School of Science, HUU. All rights reserved.

doi:10.25103/iestr.131.22
}

size of the tolerance field for the performed size, which leads to the need to correct the finishing process. An additional difficulty is represented by the processes of relaxation of residual stresses, which lead to a loss of geometric accuracy of the machined surfaces.

Evaluation of the part design manufacturability from the point of view of the achievable accuracy of its machining is very important at the stage of development and launch of new products. For this reason, the machining processes modeling of large-sized thin-walled rings is an essential element of technological preparation for the production of new aircraft engines, resulting in the guaranteed production of suitable parts with minimal cost and in the shortest possible time.

\section{Technological aspect of the design assessment of large-sized thin-wall rings}

The main difficulties in machining the type of parts under consideration are the bends of the ring wall under the action of cutting forces, as well as the unsatisfactory quality of the treated surface due to vibrations. Compared to other parts types, thin-walled parts are prone to plastic deformations during blade processing, which complicates the manufacturing process. The use of special equipment, rigidly fixing thin-walled elements, allows to improve the quality of the processed surface, but often does not allow to provide the specified processing accuracy. As a rule, this is expressed in the relaxation of residual stresses, which leads to loss of shape and geometric dimensions of the machined surface after removing the machined part.

Determination of design criteria, which to a greater extent affect the stiffness of a thin-walled part of a large diameter, will allows fast assess the technology of the product from the point of view of achievable accuracy of its machining. Rigidity - the ability of a product to resist the effects of external loads with deformations that are permissible without 
disrupting their performance. For the convenience of calculations, current study uses the parameter of geometric mechanical compliance $\mathrm{C}$, being the inverse magnitude to the stiffness value and showing the measure of the ability of a solid body to elastic or elastoplastic deformations [3]:

$C=\frac{\Delta}{F \cdot E}, 1 / \mathrm{mm}$

Where,

$\Delta$ - the size of lengthening, $\mathrm{mm}$;

$\mathrm{F}$ - the applied force, $\mathrm{N}$;

E- elastic modulus, N/mm2.

A corrosion-resistant nickel based AMS 5643alloy often being used in the manufacture of hull parts of a gas turbine engine, was studied in this research. The elastic modulus of this material is $E=1,930 \cdot 10^{11} \mathrm{~N} / \mathrm{m}^{2}$. Since the ring is a rotation type body, turning is usually used as a method of blade processing of parts of a similar design. At the same time, the value of the cutting force at the finishing processing modes is of the order of magnitude $F=1000 \mathrm{~N}$. An analysis of the design documentation of the considered group of parts for new aircraft engines of medium dimension showed that the wall thickness for them varies between 0.7-2.2 $\mathrm{mm}$, the wall height is $20-80 \mathrm{~mm}$, diameter - $600-1450 \mathrm{~mm}$. The indicated values and intervals were taken as initial data and boundary conditions when modeling the static force impact during machining.

Modeling of the forces acting during machining was carried out in the Solidworks Simulation system using the finite element method (FEM). The main idea of the FEM is that any continuous value (in our case, displacement) can be approximated by a discrete model, which is built on the set of piecewise continuous functions defined on a finite number of elements [5]. As the point of application of the load, the very nonrigid part of the part was chosen, namely, the upper point of the thin wall of the ring, which is subject to maximum displacements during machining [6].

The results of FEM simulations were analyzed according to the experimental design methodology, which is a set of measures consisting in the selection of the number and conditions of the experiments necessary and sufficient to solve the problem with the required accuracy.

The design of the experiment was used to find optimal conditions for the object operation and allowed us to determine the crucial criterion defining the compliance of the part [7].

\section{Modeling of large-size thin-walled housing rings geometrical mechanical compliance when machining}

The scheme of loading for determining the geometric mechanical compliance of a large-sized thin-walled ring depending on the variable design parameter for blade processing is shown in Figure 1. According to this diagram, the lower end plane of the ring is a seal and simulates a clamping device meeting A concentrated load was applied to the upper point of the ring on the cylindrical surface of the ring, simulating the force action of the cutter during turning.

The typical diagram obtained in the SolidWorks calculation is shown in Figure 2. The simulation results were used for estimation of the geometric mechanical compliance of large-sized thin-walled rings depending on three design criteria:
- from wall thickness S (Figure 3);

- from the diameter of the ring D (Figure 4);

- from the height of the wall of the ring $\mathrm{h}$ (Figure 5).

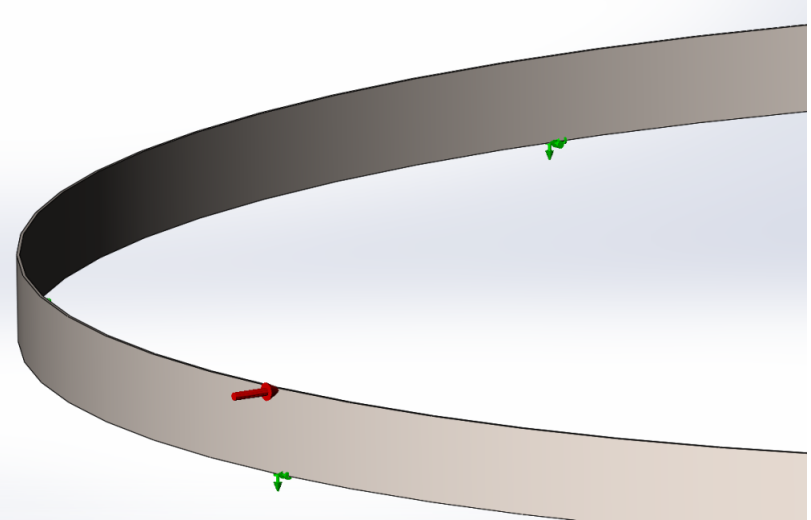

Fig. 1. The scheme of loading for determination of dependences of geometrical mechanical compliance

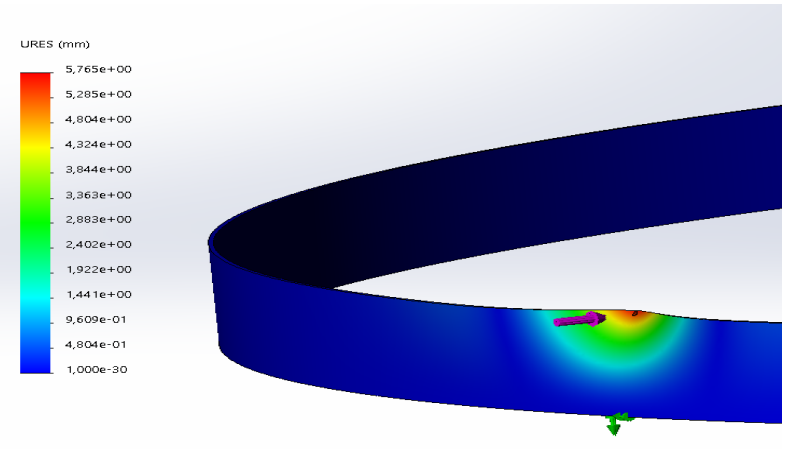

Fig. 2. The diagram of deformation to areas of the point of influence of force of cutting of the processed part

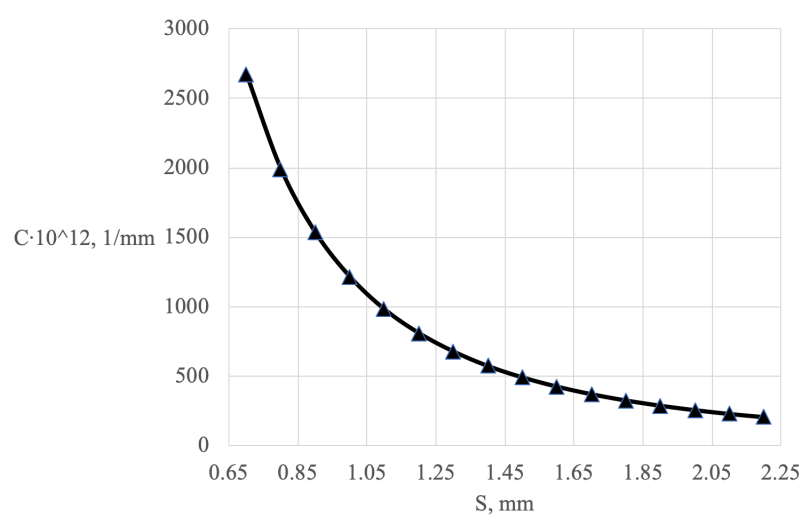

Fig. 3. The schedule of dependence of geometrical mechanical compliance of the large-size thin-walled ring with a diameter of $\mathrm{D}=1000$ $\mathrm{mm}$ and $\mathrm{mm} \mathrm{h}=50$ wall height from $\mathrm{S}$ wall thickness

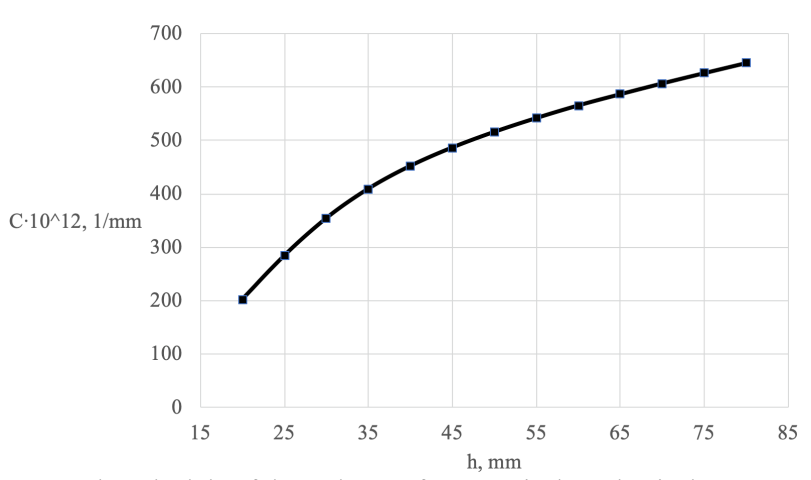

Fig. 4. The schedule of dependence of geometrical mechanical compliance of the large-size thin-walled ring with a diameter of $\mathrm{D}=1000$ $\mathrm{mm}$ and $\mathrm{mm} \mathrm{S}=1.5$ wall thickness from $\mathrm{h}$ wall height 


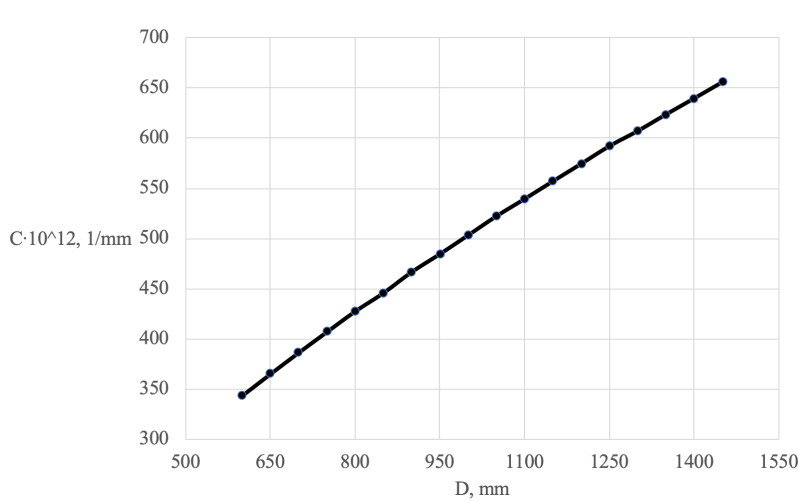

Fig. 5. The schedule of dependence of geometrical mechanical compliance of the large-size thin-walled ring with thickness of the wall of $\mathrm{S}=1.5 \mathrm{of} \mathrm{mm}$ and height of the wall of $\mathrm{h}=1.5 \mathrm{of} \mathrm{mm}$ from diameter $\mathrm{D}$

The plots presented on figures 3-5 assume the power characteristic of geometrical mechanical compliance from each of criteria in the explored area. The specified fact defined the choice of mathematical model for calculation of geometrical mechanical compliance in the following form:

$P l=C_{0} \cdot S^{a 1} \cdot h^{a 2} \cdot D^{a 3}, 1 / \mathrm{mm}$

It should be noted that in the considered of the ring thickness range, the geometric compliance value changes in more than 10 times interval. In this case, a sharp increase in compliance is observed with a corresponding decrease in wall thickness of less than $1 \mathrm{~mm}$, which supposes the presence of significant difficulties associated with blade cutting rings in the specified thickness range. According to other criteria, the dependences are more monotonous.

To assess the degree of influence of each constructive criterion on the accuracy of blade processing of a part, a planning matrix for a mathematical experiment in kind was compiled (Table 1).

Table 1. The matrix of planning of the mathematical experiment in the natural form and its results

\begin{tabular}{c|c|c|c|c}
\hline Experiment No. & Diameter, X1 mm & Height, X2 mm & Thickness, X3 mm & Movement, Y mm \\
\hline 1 & 1450 & 80 & 2.2 & 1.798 \\
2 & 600 & 80 & 2.2 & 0.9195 \\
3 & 1450 & 20 & 2.2 & 0.3469 \\
4 & 600 & 20 & 2.2 & 0.3159 \\
5 & 1450 & 80 & 0.7 & 21.99 \\
6 & 600 & 80 & 0.7 & 11.46 \\
7 & 1450 & 20 & 0.7 & 8.776 \\
8 & 600 & 20 & 0.7 & 5.765 \\
\hline
\end{tabular}

Based on the presented experimental design, the FEM analysis was performed using the Solidworks Simulation system to calculate the displacement value under given conditions. The results of the mathematical experiment are also presented in table 1 .
To assess the degree of influence of each constructive criterion on the accuracy of blade processing of a part, a planning matrix for a mathematical experiment in logarithmic form was compiled (Table 2).

Table 2. The matrix of planning of the mathematical experiment in the logarithmic form and its results

\begin{tabular}{c|c|c|c|c}
\hline Experiment No. & $\log (\mathbf{X 1})$ & $\log (\mathbf{X} \mathbf{2})$ & $\log (\mathbf{X 3})$ & $\log (\mathbf{Y})$ \\
\hline 1 & 0.34242 & 1.90309 & 3.161368 & 14.5403 \\
3 & 0.34242 & 1.90309 & 2.77815125 & 14.2491 \\
4 & 0.34242 & 1.30103 & 3.161368 & 13.8258 \\
5 & 0.34242 & 1.30103 & 2.77815125 & 13.7851 \\
6 & -0.1549 & 1.90309 & 3.161368 & 15.6278 \\
7 & -0.1549 & 1.90309 & 2.77815125 & 15.3447 \\
8 & -0.1549 & 1.30103 & 3.161368 & 15.2289 \\
\hline
\end{tabular}

The linear logarithmic regression model in the natural form received on the basis of the made experiment has the following appearance:

$\log (Y)=\log (a 0)+a 1 * \log (s)+a 2 * \log (h)+a 3 *$

$\log (D)$

where $\log (a 0)=C_{0}$ from expression (2).

In calculation result the following mathematical model of dependence of geometrical mechanical compliance of the large-size thin-walled ring on diameter, height and thickness was obtained:

$$
P l=0.99 \cdot S^{0.34} \cdot h^{1.88} \cdot D^{3.12},
$$

These coefficients indicate the degree of influence of the criteria on the ductility of the part, which means that the diameter of the workpiece has the greatest influence on the magnitude of ductility, and the wall thickness is the smallest

\section{Large-size thin-walled housing ring turning accuracy during production}

In the production conditions of NPA Technopark AT, a number of large-sized rings were turned (Figure 6) with various diameters, thicknesses and heights of thin-walled elements, the nominal values of which are shown in Table 3. Statistics of dimensional deviations during processing of these parts were collected by comparing the nominal and actually obtained diameter of the thin-walled element under consideration on the basis of a sample of 10 processed rings of each code. 
Table 3. Results of experimental large-size thin-walled rings processing

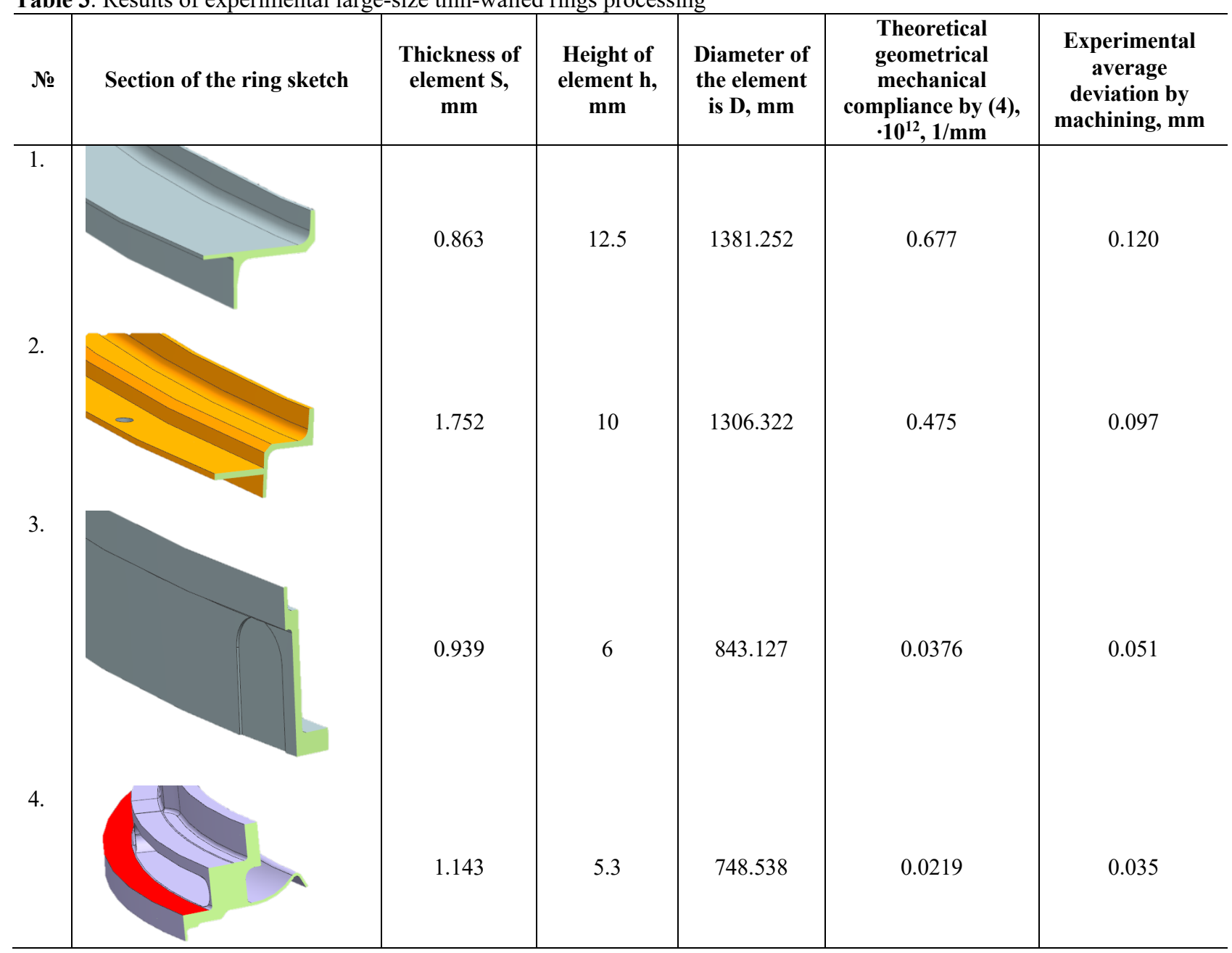

Date presented in table 3 reveal that the greatest deviation is the part with the greatest geometric mechanical compliance of the element. Moreover, for rings with proportional values of geometric compliance, for which comparable values of elements of the cutting mode are used, an almost linear dependence of the processing accuracy on the geometric mechanical compliance calculated by model (2) is observed. The absence of a proportional increase in the processing error when comparing rings with geometrical compliance differing by an order of magnitude is explained by the use of other technological cutting parameters, which can reduce the cutting force and increase the machining accuracy to acceptable values.

So, when processing thin-walled blanks of large diameter to reduce cutting forces, and, accordingly, reduce the magnitudes of the bending of the part, it is recommended to use the smallest radius of the cutting edge of the insert, the sharp geometry of the cutting wedge, etc. [8].

Different rings machining analysis showed that geometrical mechanical compliance criterion value is $\approx 0.1 \cdot 10^{12} \mathrm{~mm}^{-1}$. Housing rings which have geometrical mechanical compliance more than this value was machined firstly with insufficient accuracy by conventional technology. There are many technological decisions to reduce part bending and increase low rigidity parts machining accuracy. Some of them based on decreasing cutting force by changing speed, federate and depth of cut $[8,9,10]$. Another methods use special tool geometry $[11,12,13]$. Some methods allow to increase machining accuracy by toolpath and stock removal order $[14,15,16,17]$. Methods based on special fixtures and jaws are widely used too $[18,19,20]$. Developed model and proposed design benchmark allows defining the necessary to use these methods or to use conventional technology during new parts machining without waste losses.

\section{Conclusion}

Geometrical mechanical compliance can be use as machining accuracy criteria for large-size thin-walled aviation engine housing rings. The specified experimental data confirm reliability of the ring geometrical mechanical compliance mathematical model. Geometrical mechanical compliance criteria value for researched range of the rings (diameter is $600-1450 \mathrm{~mm}$, height is $20-80 \mathrm{~mm}$, thickness is $0.7-2.2 \mathrm{~mm}$ ) is $0.1 \cdot 10^{12} \mathrm{~mm}^{-1}$. This value shows the boundary parts design conditions when is necessary to use nonconventional technological decisions (tool, cutting mode, equipment, etc.) to provide required machining accuracy. Designers can use this value to detect the parts with bad produceability and make changes in advance to exclude problems during it production. Preliminary estimate of geometrical mechanical compliance of responsible elements of the large-size thin-walled ring on the basis of modeling of FEM allows to estimate technological effectiveness of the design in terms of edge cutting machining already at the stage of technology preparation of production and to take the appropriate measures for the defects exception. 


\section{Acknowledgement}

The article was prepared with the assistance of Bashkortostan Republic Academy of Science during Young Researcher Grant 2019 work performance.
This is an Open Access article distributed under the terms of the Creative Commons Attribution License

\section{References}

1. Increase in efficiency of production of parts of GTE on the basis of forecasting of the cutting properties of tool hard-facing alloys / Postnov V.V., Hadiullin S.H., Starovoytov S.V.//STIN. 2015. No. 11. Page 20-26

2. Analysis of the reasons and sources of emergence of residual stresses / Basharov R.R., Kilmetova L.R., Starovoytov S.V., Hadiullin S.H., Chernikov Items//Bulletin of the Ufa state aviation technical university. 2018. T. 22. No. 4 (82). Page 3-11

3. Way of determination of rigidity of the CNC machine / Kudoyarov R.G., Basharov R.R., Fetsak S.I.//In the collection: Machine-tool construction and the innovation mechanical engineering. Problems and points of growth Materials of the All-Russian scientific and technical conference. Ufa, 2018. Page 260-265

4. SAE AMS5643U-2016 Steel, Corrosion-Resistant, Bars, Wire, Forgings, Mechanical Tubing, and Rings $16 \mathrm{Cr}-4.0 \mathrm{Ni}-0.30 \mathrm{Cb}$ (Nb) - 4.0Cu Solution Heat Treated, Precipitation Hardenable UNS S 17400

5. A 2D computer model of cutting of the A2024 aluminum alloy/Khalikova G.R., Bikmeyev A.T., Gazizov R.K., Vairis A.//Journal of Engineering Science and Technology Review. 2014. T. 7. No. 5. Page $24-28$

6. Theoretical and experimental stress-strain analysis of machining gas turbine engine parts, which made of the high energy structural efficiency alloys/Postnov V.V., Starovoitov S.V., Fomin S.Y. Basharov R.R.//Journal of Engineering Science and Technology Review. 2014. T. 7. No. 5. Page 47-50

7. Using experiments to construct mathematical models for machinability characteristics of a heat resistant aluminum alloy/Usmanov B.F., Starovoitov S.V., Khadiullin S.K., Valishina Z.R.//Journal of Engineering Science and Technology Review. 2014. T. 7. No. 5. Page 51-54

8. Predicting the cutting properties of hard alloys for the manufacture of components used in gas-turbine engines/Postnov V.V., Khadiullin S.K., Starovoitov S.V.//Russian Engineering Research. 2016. T. 36. No. 6. Page 496-501

9. A stability analysis of turning a tailstock supported flexible workpiece/Chen C.K., Tsao Y.M.//International Journal of Machine Tools and Manufacture. 2006. T. 46. № 1. C. 18-25.
10. Optimization of process parameters during turning of Inconel 625/Waghmode SP, Dabade UA.//Mater. Today Proc. 2019, S2214785319331256. (doi:10.1016/j.matpr.2019.08.138)

11. FEM based Cutting Velocity Selection for Thin Walled Part Machining/Scippa A, Grossi N, Campatelli G.//Procedia CIRP 14, 2014., 287-292. (doi:10.1016/j.procir.2014.03.023)

12. Effects of material microstructure and surface microscopic geometry on the performance of ceramic cutting tools in intermittent turning/Cui X, Wang D, Guo J.Ceram//Int. 44, 2018, 8201-8209. (doi:10.1016/j.ceramint.2018.01.269)

13. Performance investigation of surface roughness in hard turning of AISI 52100 steel - RSM approach/Pradeep Allu V, Linga Raju D, Ramakrishna S. Mater//Today Proc. 18, 2019, 261-269. (doi:10.1016/j.matpr.2019.06.299)

14. $\mathrm{CAD} / \mathrm{CAM} / \mathrm{CAI}$ application for high-precision machining of internal combustion engine pistons/Postnov V.V., Khadiullin S.K., Starovoitov S.V., Kilmetova L.R.//Journal of Engineering Science and Technology Review. 2014. T. 7. № 5. C. 66-69.

15. Geometric error modeling and compensation of horizontal CNC turning center for TI worm turning/Ding S, Song Z, Wu W, Guo E, Huang X, Song A.//Int. J. Mech. Sci. 167, 2020, 105266. (doi:10.1016/j.ijmecsci.2019.105266)

16. Computer-aided error modeling approach to improve the accuracy of turning processes/Mou J.//Comput. Ind. 24, 1994, 71-80. (doi:10.1016/0166-3615(94)90009-4)

17. Tool path generation of ultra-precision diamond turning: A stateof-the-art review/Gong $\mathrm{H}$, Ao S, Huang K, Wang Y, Yan C.//Nanotechnol. Precis. Eng., 2019, S2589554019300339. (doi:10.1016/j.npe.2019.10.003)

18. Qualifying multi-technology machine tools for complex machining processes/Brecher C, du Bois-Reymond F, Nittinger J, Breitbach T, Do-Khac D, Fey M, Schmidt S.//CIRP J. Manuf. Sci. Technol. 13, 2016, 1-14. (doi:10.1016/j.cirpj.2015.11.001)

19. Virtual machining system simulator: analysis of machine tool accuracy/Theissen N, Laspas T, Szipka K, Archenti A.//Procedia Manuf. 25, 2018, 338-343. (doi:10.1016/j.promfg.2018.06.101)

20. A machining-feature-driven approach to locating scheme in multiaxis milling/Wan X.-J., Xiong C.-H., Zhang X.-M., Xiong Y.-L., Wang X.-F.//International Journal of Machine Tools and Manufacture. 2010. T. 50. № 1. C. 42-50. 